\title{
The Development of Students Key Professional Competencies In the Process of Didactic Tasks Realization
}

\author{
Yuri M. Litovchin ${ }^{1}$, Natalya L. Avilova ${ }^{2}$, Irene A. Podvoiska ${ }^{1}$, Azat S. Valeyev ${ }^{3}$, Elena A. Yesina ${ }^{1}$, Roza V. \\ Gataullina $^{4}$ \& Liliya R. Islamova ${ }^{4}$ \\ ${ }^{1}$ Humanities institute of TV \& Radio broadcasting named after M. A. Litovchin, Moscow, Russia \\ ${ }^{2}$ Russian State University of Tourism and Service, Moscow, Russia \\ ${ }^{3}$ Sibay institute (branch) of Bashkir State University, Sibay, Russia \\ ${ }^{4}$ Kazan State Agrarian University, Kazan, Russia \\ Correspondence: Yuri M. Litovchin, Rector of Humanities institute of TV \& Radio broadcasting named after \\ M.A. Litovchin, 119180, Brodnikov per., 3, Moscow, Russia. E-mail: yessina@yandex.ru
}

Received: May 7, 2015 Accepted: May 16, 2015 Online Published: May 28, 2015

doi:10.5539/jsd.v8n3p285

URL: http://dx.doi.org/10.5539/jsd.v8n3p285

\begin{abstract}
The relevance of the problem how to form the high school students' professional competences is due to the fact that professionals with "competencies", which have versatile abilities confirmed by practical experience of independent socio - professional problems are demanded. The results of the study indicate that didactic tasks become the most effective resources in this process, which transform the learning goals of the teacher into a productive construct for key professional competences developing in learning and professional activity. In this regard, this article is focused on the scientific and methodological justification of instructional tasks' basic components' structure and content aimed at the development of university students' key professional competencies. The leading method to study this problem is monitoring of students' key professional competencies' formation in the process of didactic tasks' realization. The article presents the theoretical and methodological bases of students' key professional competencies' formation in educational tasks systematic using as a set of knowledge, skills, qualities, experience, and operationally practical ways of activities necessary for professionally - oriented functions' creative performing. The article can be useful to high school teachers, young scientists, graduate students, university Methodists, the students of the teachers' advanced training and retraining system.
\end{abstract}

Keywords: didactic objective, qualifications, key skills, competence, competence, core competence, competence approach, cultural competence, professional competence, monitoring

\section{Introduction}

\subsection{The Urgency of the Problem}

The relevance of research is defined by undergone demands to high school students' training - future specialists of the new generation, possessing the qualifications which advance the requirements of mobile transforming labor market: flexibility to adapt to changing conditions; to develop key competencies that can be skillfully applied in practice to address emerging issues; to think creatively and critically; to be able to see emerging problems in the professional activity and to seek ways of their rational solution, using modern technologies; to understand clearly where and how their acquired knowledge can be applied in reality; to be able to generate new ideas; to work correctly with the information; to be able to organize the evidence needed to solve specific problems, to analyze them, to propose a hypothesis of problems' solving; to carry out the necessary generalizations, comparing them with similar or alternative solutions; to formulate reasoned conclusions; to apply the obtained results for emerging issues' solving, etc. (FSES of HPE (federal state educational standards of high professional education) in areas of training, 2009). In connection with such areas of training in the current standards the problem of qualifications' and competences' harmonization is actualized, identified with the goals of education, its active core of quality standards.

The results of the study show that competency-based approach to future specialist training directs the educational program on the labor object, their characteristics' ratio. But this approach in educational practice of higher 
education institutions doesn't determine the level of abilities' connection, readiness, knowledge and attitude to work with the effective functioning of the individual. Qualification just means the predominance of the "framework" activities in sustainable professional fields and algorithms. As for competences: they correspond to the imperatives of the mobile professional boundaries, the dynamics of professions, their globalization; lead to destruction of professional isolation; acts as the contextual appropriateness of creativity, context - role self-determination (self-organization, self-management, self-estimation, self-regulation, self-correcting, self-transformation) of personality (Khutorskoy, 2003). Learning from the universities' experiences of the students' key professional competencies' development shows that this process allows educational institutions to modernize training objectives and orientations from knowledge reproducing to their use and organization; to remove the dictatorship from the labor object (subject matter), but not to ignore it; to put in its base a strategy for flexibility increasing in favor of employment opportunities' and tasks' solving increasing; to put at the forefront the interdisciplinary and integrated requirements and expectations of the educational process; to integrate educational goals with situations of applicability (using) in the world of labor; to direct the activities on the endless diversity of professional and life situations (Zeer, 2000). The expected results of students' core professional competences' formation in the educational practice of higher education institutions are accumulated in the complex of pedagogical conditions providing innovative update of the educational process, among which the most productive and appropriate condition for students are didactic objectives as an educational construct of core competencies' integrity in learning and professional activity (Zimnaya, 2003).1.2 Theoretical and Methodological Novelty of the Research Problem

The theoretical and methodological novelty of the research problem consists of:

- conceptual ideas of students' core professional competencies' formation in the process of didactic tasks' realization as a strategy for the future specialist training, with a highly developed intellectual potential, formed integrity of professional key competencies required for individual self-determination in the conditions of transforming mobile manufacture;

- the requirements for a predictive model of a specialist, conventionally grouped in three areas: professional level of young professional (professiogram), his or her personal qualities (technogram), the willingness of the individual to professional work (psychogram);

- the underlying components of didactic tasks, defining the content of students' key professional competencies;

- the organizational structure and substantive components of the package of key professional competencies oriented on integration with a predictive model of basic manufacture specialist.

\subsection{Practical Significance of the Research}

Practical significance of the research is determined by the productivity of educational curricula materials for students' core professional competencies forming in the process of didactic tasks' realization on various cycles' disciplines.

\subsection{The Theoretical Basis of the Research Problem}

Theoretical and methodological basis of research consists of: the concept of students' learning and cognitive activity enhancing (Ball, 1990; Zimnaya, 2003;Zhuikov, 1966; Lerner,1972; Matyushkin, 1972; Makhmutov, 1975), the modern concepts of competence-based approach (Baidenko, 2006;Zimnaya, 2006; Ivanov, 2008; Novikov, 2000; Khutorskoy, 2003), studies on the competent specialist personality formation (Gilmanshina, 2007; Deneko, 2006; Kirsanov, 2005; Kondratiev, 2000; Shchelkunov, 2010).

The theoretical basis of the study is presented by key concepts (didactic objective, qualifications, key skills, competency, competence, core competence, competence approach, cultural competence, professional competence, monitoring), a set of principles of competence-based approach (personal goal setting, integration, interrelationship, the compliance of didactic units to the content of key professional competencies, design, self-determination, correction), the complex of pedagogical conditions of university students' key professional competencies' formation in didactic tasks' implementation (the basic components of didactic tasks, tasks' classification, structure and contents of key professional competencies' pack).

\subsection{Research Methods}

To achieve the objectives of the study a complex of methods is involved: theoretical (analysis of literature: philosophic, psychological, pedagogical and methodical; legal documents, the requirements of the FSES of HPE; electronic resources; university teachers' innovation and mass teaching experience; educational curricula, textbooks and manuals of traditional, innovative and original types); empirical (observation, testing, 
self-assessment, peer review, methods of data processing and the hypotheses proposed verification, monitoring, formative experiment of the didactic tasks' basic components' applicability in the process of students' key professional competences' establishing, expert assessment of the available data).

\subsection{Criteria Base}

The indicators of university students' key professional competences in didactic tasks' implementation, according to the results of the study are: readiness to their manifestation (motivational aspect), possession of the tasks' basic content knowledge (cognitive aspect), the experience of existence in standard and non-standard situations (the activity aspect), attitude to the implementation's content and object (axiological aspect), the emotional volitional regulation of process and result manifestation. Established indicators of students' key professional competencies' formation determine the content of didactic tasks' basic components' justified by the goals of the educational process (intrasubject, interdisciplinary, pre-batch), and professional activity imitation purposes(diagnostic, design, reflexive). The complex of these tasks is determined by the assessment criteria of the mastered didactic objectives content: 1) to define the issue in the task: students independently determine the solution, they control themselves in solution correctness; 2)"to understand the task": to use the knowledge and skills for information understanding, presented in the form of text, diagrams, charts, tables, to synthesize information from a variety of sources; 3 ) "to characterize the task": to define the variables presented in the problem and the relationships between them, to build hypotheses, critically evaluate information; 4) "to present the task": to develop a form for information presentation, to pass from one representation form to another; 5)"to solve the problem": to make decisions in accordance with the terms of the task, analysis, planning and execution to achieve the goal; 6)"to think over the decision": to investigate the obtained solution and, if necessary, use additional information, to evaluate the decision; 7) "to inform about the decision": to choose the form of presentation of the result obtained and to convince others of its correctness.

\section{Methodological Framework}

\subsection{Key Concepts}

Qualitative and quantitative indicators of the results of the study contribute to the discursive updating of key concepts content:

- didactic task: the learning task, involving the search of new knowledge, methods, (skills) and motivation for creative implementation connections, relations, evidences active use in teaching process (Makhmutov, 1975). Variety of tasks in the educational process depends on the characteristics of subjects, their place in the system of knowledge and skills, age group of students. Science - based system of teaching tasks has learning potential of all functions of students'-future specialists' professional training, it is determined by the subject matter or terms (methods) of its decision, and it is a specific part of the overall framework. In modern conditions of university educational process renewal instead of specific assignments doing the students are required ability to solve new problems (new activities, new products). These new challenges provide a high level of theoretical and practical training, the ability to make decisions ability to communicate with people, ability to formulate the problem and task independently and to find its solutions;

- qualification: level of training, suitability for any kind of work; knowledge, experience, quality, level and type of professional training required to perform job functions majoring on the post;

- key qualifications - a set of core competencies, competences and net professional qualities;

- competency - a set of universal knowledge of the individual, including General scientific and General professional categories, concepts, laws, principles and patterns of students' - future specialists' creative potential realization in modern activities;

- competence - a set of related personality qualities (knowledge, abilities, skills, experience, generalized activity methods), defined relatively to a particular range of objects and processes, providing productive performance of professional activities. These are the personal abilities to implement his or her competence;

- key competencies - person's abilities and readiness for effective professional activity and social interaction. Practical experience of application of these competencies is manifested as competency of the future specialist, i.e., core competence becomes such one only in action, in the application of this competence in a particular professional and life situations;

- competence-based approach - an educational strategy based on innovative instrumental constructs: competency, competencies, and net professional qualities, together representing a key qualities of the individual specialist, focused on productive realization in activity his or her intellectual and creative potential, motivated and ready to work, to self-realization and self-transformation in complex socio - professional conditions of 
transforming society;

- net professional qualities - skills, characteristics, experience of the individual, defining the terms of his or her reference in social and professional activities, differentiated on two grounds:1) the qualities of coverage (cognitive, regulatory, and communication); 2) qualities of narrow radius- the steps required to accomplish a specific group of professions: man-man, man-tech, man-nature, man-sign system, the man-art image (Zeer, 2000);

- monitoring - the systematic diagnostic tracking of professional educational process;

- cultural competence - a set of knowledge, skills, qualities, personality experience, determining his or her readiness to act in conditions of cultural transformation of the society, to build their own picture of the world individual beliefs, life, work, communication, behavior, education, and upbringing, assimilation of new values based on the socio-cultural experience, etc.;

- professional competence - a set of knowledge, skills, qualities, personal experience, determining his or her readiness for competent creative process, critical assessment of the results of their work in the main types of professional activity.

\subsection{A Set of Principles}

- personal goal setting - focus on the personality of the student - future competent professional in modern employment areas;

- integration, harmonizing learning objectives with the objectives of professional activity;

- the relationship of the educational process requirements to the individual student with the manufacture requirements to the personality of the future specialist;

- compliance of academic subjects didactic units' content to the content of the competencies reflected in specialist's predictive models (professiogram, psychogram, technoram);

- the design, aimed at the development of students' key professional competencies required for research, design, problem - based, creative learning and cognitive activity;

- self-determination, manifested in the individual trajectories design of self-determination, self-transformation, self-organization, self-realization in educational and professional activities, ensuring the level of value orientations in accordance with the personal claims;

- correction, clarifying the didactic units of the disciplines' studied cycles according to the curriculum of the University and the decrease in pragmatic orientation of professionally important competences recommended by the manufacture.

\subsection{The Complex of Pedagogical Conditions}

The complex of pedagogical conditions is presented by the basic components of University students didactic tasks and the classification of tasks on the purposes of learning activities and objectives of simulate professional activities.

The basic components are designed on the base of model tasks presented in the occupational classification "as an action directed at a specific business purpose under specified conditions" (Kondratiev, 2000), and differentiated in the educational process according to the types of educational activity on intrasubject (cognitive actions), interdisciplinary (almost transformative algorithm of actions), pre-batch (reflection, innovation).

Classification of tasks: in university educational process is carried out on types of work situations simulation, their solving, development of technological projects, individual assignments, etc. in accordance with the core components of professional activity. In the research process, the types of tasks that make up the core of operationally practical component of professional activity are established, having the properties of generality, reality, personal determination of students: on intra -, inter-disciplinary and pre-batch levels:

- diagnostic tasks are tasks, not so much extending the students' evaluation knowledge about the real state of the intended object of conversion, but simulating the ideal image of an object, capable of becoming a target orientation in upcoming activities;

- design, which suggest the consideration of the problem in its development and the results' forming: subject area - problem situation - task - determining of simulation method - brainstorming - hypotheses proposingresearch searching work - discussion in small groups -results shaping - the project protection-conclusions making, recommendations; 
- reflex - which are oriented not only on assessment of manufacture, but also of human result of the task. The task course and the relations system established between the students in the decision process are under the influence of reflex.

\section{Results}

\subsection{The Modern Discourse of Ideas, Concepts, Categories, Key Professional Competencies of University Students}

It is determined by the necessity transform modern universities. The lack of implementation in this process runs the risk of turning the education system's modernization strategy in a simple Declaration. It is obviously, that this contradiction is internal leitmotif of much debate of scientists in the academic community and practitioners in Russian universities regarding the conceptual framework of the competence approach. The positions' diversity in the discursive content definition of key competences is closely related to the idea of objectiveness and focus of learning process in which the competencies set higher and generalized level of students' abilities and skills, and the content of education continues to be defined by the basic components (knowledge, skills, experience of creative activity and the experience of value relations). Semantic content of the notion "core competencies" are filled as by the meanings of the European key competences so the Russian classification, which present axiological, cultural, educational, informational, communicative, social and employment competence and competence of personal self-improvement. In addition, there are divergent interests of all actors involved in this process: the state, having experience with the characteristics of the qualification, i.e., a clear list of knowledge and skills that are relevant from the point of view of high education diploma receiving; employer, giving priority to basic communication, information competency, and experience in the specialty and recommendations; by graduates seeking the prestige of the diploma, providing the possibility of implementing career ambitions. Therefore, the domestic classification of key competencies not only differ in meaning, but also due to the needs of different actors, which makes it difficult for an objective assessment and requires the development of different diagnostic procedures by content and structure.

The measurement of the levels in competences development requires a serious correction and modification, as stated in the standards of graduates competencies in a particular field of study (specialization), subdivided into General cultural (GCC) and professional (PC), suggest not only the development of a Toolkit for the monitoring implementation and activities and test package evaluation, but also the design of scientifically proved competencies classification.

The quality of higher education, determined by the needs of the evolving society and labor market in specialists of a specific level and needs of the individual in higher education emphasize the development of a model of the "ideal student", having the highest attainable standard of development of General and specific competences. In doing so, individual competences depend on the direction of training in higher education system. In this case it comes to the most versatile core competencies - factors of behavior that are important for the implementation of tasks of productive activities in different spheres and in different positions.

Assessment of the developed competence's level- is the urgent problem of quality diagnostics, their use in educational process of a University. A major problem in this aspect is the development of universal criteria, because it is important for student's future professional activity not only knowledge but also the ability to apply it in practice.

Indicators of these criteria severity are: presence, depth, breadth of knowledge; the needs' content and development; the system of value orientations and social norms which are necessary for guiding in various fields; ideals and the degree of involvement in creative, training educational, professional and socio-cultural activities. Criteria of key professional competencies formation in this study are represented by the willingness of students to exercise competences in the implementation of didactic tasks (motivational aspect), the possession of tasks content knowledge (cognitive aspect), experience in a various standard and non-standard tasks implementing (the activity aspect), attitude to the content and object of tasks implementation (axiological aspect), aspect of the emotional - volitional regulation of the process of tasks and their results implementation.

The identified criteria and indicators help to set priorities among university students' key professional competences relevant to the goals of education, the structural view of social experience and experience of the individual, and the level of professional development of students, helping them to master social experiences, gain life skills and practice in modern society. All this served as the basis for the development of the structure and content of the package of students' universal key professional competences, adapted to different sectors and different levels of functions through the implementation of didactic tasks in the educational process of the University: 
- general professional competence - is the end result of a learning activity taking place according to the algorithm: recognition - introduction to new material (the implementation of intra-task); understanding - knowledge creation (implementation of an interdisciplinary task); reproduction of knowledge in operationally practical tasks; transfer - creative interpretation of the received information (implementation of pre-batch tasks);

- technological competence - algorithmic and functional skills, knowledge of information and communication technologies, decision-making skills, systematic thinking, results-implementation of didactic tasks in the optimum time (achieved in the implementation of intra-task, and interdisciplinary pre-batch tasks);

- communication skills - ability to assume managerial and leadership qualities, ability to work in a team, building of relationships in the team (achieved in the implementation of interdisciplinary and pre-batch tasks);

- social competence - are modern personality characteristics which are sought by employers: initiative, responsibility, focus on self-development and self-transformation, adaptability, positive thinking, stress tolerance (pre-batch tasks implementation).

\subsection{Classification of Didactic Tasks}

In our study to design didactic tasks classification a competence-based approach's basics are used, oriented on implementation of intensive and extensive resources of the university educational process in specialists' training needed by the labor market. The essence of the competence approach is to reassess ideas of problem - based learning, which incorporates the phased implementation of specific logical steps (the choice of topic (task) subject area, definition of the problem situation, the problems, the use of design technologies, search, results, prediction of findings, identification of prospects) in forming of common cultural and professional competences of students in the educational process of the University. These ideas differently define the objectives, principles, content, students' training technology, stimulate their cognitive (thinking and training and production) activities, and cognitive activation is achieved through the task, the job, the exercise in their harmonious interaction.

Analysis of the rich heritage of the national didactic school (Davydov, 1996; Zhuikov, 1966; Lerner, 1972; Matyushkin, 1972; Makhmutov, 1975) determine the tasks' value in the development of university students' cognitive activity. In their works they write that during that time a wide variety of tasks was used for learning, repetition and consolidation, that is, for mastering the system of scientific knowledge. Tasks can be typical (standard), training, for material repetition, to develop the skill of applying one or another method of solution, etc." (Makhmutov, 1975). In 60-ies of the last century there were two meanings of the term "task" in the theory and practice of pedagogical science: the first is any task, which requires the implementation of any cognitive act; the second is a cognitive task, the solution of which leads the student to new knowledge and ways of action. The following meaning becomes innovative one in the discourse of the problem: "Cognitive task - the task, involving the search of new knowledge, techniques (skills), and stimulation of active use in teaching relations, evidence" (Makhmutov, 1975). Existing set of tasks and their definitions and in a greater extent the achievement of problem - based learning was the basis for dividing them into two classes: problematic and non-problematic.

Non-problematic tasks are tasks on the model. The previous experience of the learner contains a way to solve them. In the process of solving such problems the result doesn't bring the learner to the new state (level of development remains unchanged) and only the skill of a known solving manner is improved.

As for the problematic task - main condition of their solution is the presence of links between the given objectives and the previous knowledge of the individual, understood as a system of concepts between the requirements of the task and the individual's ability to find a new way of decision. Successful problem solving, thus, raises the level of mental abilities of the learner and is defined as his or her new state.

Cognitive tasks, which were used to enhance the students' intellectual activity in high schools, were determined by the properties of their generality. It is an integrated property due to the presence of task complexity, characterized by problematic content of the task, methodical way of tasks setting (for example, by verbal, pictorial, artistic expression, personal, subjective attitude of students to the teacher's task). In other words, if the student perceives the task as a problem and solves it independently, this moment is the most important one in the development of his intellectual abilities. The result of scientific research and experimental work in the theory and practice of pedagogical science of the past century has become widely used in educational institutions at all levels, including the universities, types of cognitive tasks, and it has not lost its significance up to the present time: problem with not formulated issue; with missing data; with redundant data; with multiple solutions; with changing content; on proof; on thinking, logical reasoning.

But in today's changing conditions, a goal of professional education is determined by the ultimate goal of future specialists' training - educated one, with a high level of General and professional culture, developed intellectual 
capacity, mobile and prepared to be active professional and socio-cultural activities. In their future professional activity University students have to focus more on individual work, independent decision-making based on self-monitoring, analysis, synthesis, comparison, abstraction, proof, refutation. Hence the training goals are expanded. They are not limited to professional competency in the subject area. They are completed with competences from the field of General and professional culture that is different and determines the staging of the traditional educational and vocational important tasks focused on new activities, new products. Reconstruction of professional activity in the course of these problems' solving is fulfilled mainly at the expense of productive pedagogical method of production situations' simulation, their solutions, the development of technological projects, individual assignments, designing, for example, systems of technological security, etc. The choice of simulation techniques is preceded by preparatory work on the assessment of the efficiency and the maximum compliance to the basic components of professional activity, tasks' identity, differentiated by types of simulated professional activities:

- this task, which is not so much expanding evaluative knowledge about the real state of the intended object of conversion, but simulating the ideal image of an object, capable of becoming a target in upcoming activities;

- project, which involve the task's consideration (problems) in its development and the results of the decision: subject area - problem situation - task - determining the simulation method - brainstorming - hypotheses proposing - research search work - discussion in small groups - registration of results - preparation of conclusions, recommendations;

- reflective, which is oriented on the assessment not only of manufacture, but also human task result. The course of the task and the system of relations established between the students in the solving process are to be reflexive. Reflexivity is the student's focus on the treatment of each other in a new capacity with the height of new experience of joint activity, a vision of themselves "here and now", is a retrospective look at the past, it is a vision into the future professional activity.

The established types of tasks form the core of operationally practical component of future specialist's professional activity (Ivanov, 1997). As evidenced by the results of the study, these types of problems accompany the whole process of learning, have the properties of generality, problematical, personal determination of students with the task and are distributed in accordance with the objectives of the educational process at intra -, inter-disciplinary and pre-batch.

Intrasubject tasks are the tasks used in the process of studying the content of a particular discipline at a prescribed stage of the curriculum. Intrasubject tasks are classified according to the definitions of the various activity functions and specific conditions on assessment one with missing data, with redundant data, with multiple solutions, with changing content, on proof, on thinking, logical reasoning. The leading idea of the tasks of this type is the development and activation of cognitive and intellectual activity of the students.

Interdisciplinary tasks is a complex of tasks - stereotypes, which have algorithm for solving and creative, heuristic tasks-based on alternative choosing of the best option from several existing, pre-established methods and approaches to solve them. The complex of these tasks are complementary to each other, creates a creative, project - developing environment for the formation of students' key professional competences of different levels of training:

- to define the task. The student formulates the task, determines its solution, solve and control the correctness of its solution, thereby increasing the level of readiness to use his or her key professional competencies;

- to understand the task is to use the knowledge and skills for understanding the information presented in the form of text, diagrams, charts, tables, to synthesize information from a variety of sources;

- to characterize the task is to determine the variables presented in the problem and the relationships between them, to build hypotheses, critically evaluate information;

- to submit a task - to design a form for submission of information, to pass from one representation form to another;

- to solve the problem is to decide in accordance with the conditions of the problem, to do analysis, planning to achieve the objective of a solution;

- to think on the solution - to explore the solution obtained and, if necessary, to seek additional information, evaluate its solution;

- to inform about the task solution is to choose the form of presentation of the result and arguments their own decisions' productivity protection. 
Pre-batch tasks are tasks that simulate a variety of professional situations. This kind of task is characterized by high level of creativity, problematic, diagnosis, project and reflection in accordance with the content of future specialists' professional training. Complex of pre-batch tasks is provided with the informational component of theoretical and practical assignments, accuracy and depth of their learning and tasks' generalization (tasks reflect the basic functions, types of creative activity of the future specialist, reflection, outstripping principles and approaches to innovative solutions' finding of key professional competencies' application).

The correlation of didactic tasks and students'-future specialists' key professional competence is evident in their focus on exploratory search, creative solution resulting from professional activities problems. As unifying component of competencies and tasks performs poly-component algorithm of cognitive actions inherent to intrasubject tasks, virtually converting sequence of actions, prevailing in interdisciplinary tasks, reflection and innovation, which are dominant in the pre-batch tasks.

\subsection{A Package of University Students' Key Professional Competences}

In our study, the integral structure and content of teaching and learning materials is defined, which accompany the process of formation of university students' key professional competencies based on the ideas of competence-based approach. The priorities of key professional competencies are defined by the target orientations of personal, social, professional and cultural status of a student - the future competent specialist, demanded by the labor market and have properties of meta-subject (universal) and subject character. A meta-level of competences involves social and professional knowledge, skills, qualities and experience of the individual student - a future specialist with universal character items for any discipline cycle. Subject level is mediated by the content of the disciplines and at the same time the content of the competences mediates and modifies didactic units of any discipline. This interdependence allows to organize the curriculum, program, thematic modules in a new way and to express them not in the structure of disciplines but in the content of competencies. This process determines the relevance of the competencies' development in each discipline with respect for the goals and objectives of the studied discipline; requirements for knowledge, abilities, skills, qualities and experience of students; requirements to graduate, expressed in the job description; the use of research, problem - based, creative, design technologies; planning and evaluation of the complexity of students; criteria evaluation of knowledge mastered by students; criteria for the competencies assessment.

\section{Discussion}

The productivity of the research problem is confirmed by the results of experimental work in educational practice of higher education institutions in the process of rethinking of the didactic tasks' structure and content based on the ideas of competence-based approach and their correlation with core competencies of meta- subject and subject character.

Table 1. Dynamics of development of students' key professional competencies in the didactic tasks' implementation

\begin{tabular}{llcccc}
\hline № & \multicolumn{1}{c}{ Key professional competencies } & \multicolumn{3}{c}{ Indicators of their development } & Indicators' increase \\
& & \multicolumn{3}{c}{ average values } & \\
\hline 1. & Knowledge operating & 5,9 & 7,5 & 7,8 & $+3,6$ \\
2. & Design of activity strategy & 4,7 & 7,8 & 8,1 & $+5,5$ \\
3. & Choice from the alternatives & 6,6 & 7,3 & 8,5 & $+2,3$ \\
4. & Self-changing & 6,4 & 7,0 & 7,2 & $+3,1$ \\
5. & willingness to innovations & 5,4 & 6,3 & 8,7 & $+3,9$ \\
6. & average value & 6 & 7,3 & 8,2 & $+3,5$ \\
\hline
\end{tabular}

Expert assessment of students' key professional competences' formation in the didactic tasks' implementation, notes a marked increase in the indicators of competences' development.

\section{Conclusion}

Theoretical and practical significance of the problem of the university students' key professional competences' formation in the didactic tasks' implementation undoubted, as it defines didactic tasks' new role and place in competent specialists' training, demanded by the labor market, determines the need and importance of 
restructuring of academic subjects' didactic units, harmonize them with the competencies, direct on specific objects of labor. This approach objectively becomes an integration factor of the educational environment and creates prerequisites for an integrative field's creation outside of this environment.

\section{References}

Baidenko, V. I. (2006). Identification of graduates' competences as a necessary stage in designing SES of HPE (state educational standards of higher professional education) of new generation. Moscow.

Ball, G. A. (1990). The theory of learning tasks. Moscow.

Davydov, V. V. (1996). The theory of developmental education. Moscow.

Deneko, M. V. (2006). Professionalism and professional competence. Saint - Petersburg.

Federal state educational standard of higher professional education in areas of training. (2009). Moscow.

Gilmanshina, S. I. (2007). Competence approach in higher professional education. Kazan.

Ivanov, D. A. (2008). Competences and competence-based approach in modern education. The Director of studies, 1, 8-11.

Ivanov, V. G. (1997). The content design of high technical school teachers' professional - pedagogical training. Kazan.

Khutorskoy, A. V. (2003). Key competences. Design technologies. People's education, 5, 14-19.

Kirsanov, A. A. (2000). Methodological problems of specialist's predictive model creating. Kazan.

Kondratyev, V. V. (2000). Fundamentalization of specialist's professional education at the technological University. Kazan.

Lerner, I. Y. (1972). Cognitive tasks in teaching Humanities subjects. Moscow.

Makhmutov, M. I. (1975). Problem-based learning (the basic theory). Moscow.

Matyushkin, A. M. (1972). Problem situations in thinking and learning. Moscow.

Shchelkunov, M. D. (2010). Education in XX1 century: facing the new challenges. Kazan.

Zeer, E. F. (2000). Psychology of personality - oriented vocational education. Ekaterinburg.

Zhuikov, S. F. (1966). Academic and cognitive tasks in chemistry. Soviet pedagogy. 1, 10-23.

Zimnyaya, I. A. (2003). Key competences - a new paradigm of education. Higher education today, 5, 34-42.

Zimnyaya, I. A. (2006). Competence-based approach: What is its place in the system of modern approaches to the problem of education?: the theoretical - methodological aspect. Higher education today, 8, 20-26.

\section{Copyrights}

Copyright for this article is retained by the author(s), with first publication rights granted to the journal.

This is an open-access article distributed under the terms and conditions of the Creative Commons Attribution license (http://creativecommons.org/licenses/by/3.0/). 